\title{
DESLOCAMENTOS INTRA-URBANOS E ESTRUTURAÇÃO SOCIOESPACIAL NA METRÓPOLE BRASILIENSE
}

\author{
Maria Célia Silva Caiado
}

Resumo: O objetivo do artigo é avaliar as alterações na distribuição e mobilidade espacial da população, que podem ser associadas ao processo de urbanização e estruturação intra-urbana na Região Integrada de Desenvolvimento do Distrito Federal e Entorno - Ride. A região apresenta especificidades relacionadas ao processo de desenvolvimento econômico, à ocupação territorial e à gestão urbana, que a diferencia das demais regiões metropolitanas nacionais. Contudo, assemelha-se a elas no que se refere às desigualdades no processo de distribuição da população.

Palavras-chave:Deslocamentos intra-urbanos. Distribuição socioespacial da população. Estruturação intra-urbana.

\begin{abstract}
The objective of this paper is to evaluate the alterations in the distribution and in the socio spatial mobilite of the population that may be associated to the urbanization process and to the intra urban structuring in the Ride - Integrated Region of Development of Federal District and Adjacency. The Ride presents specific characteristics related to the process of economical development, to the territorial occupation and to the urban administration, which differs it from the other urban agglomerations and from the national metropolitan areas, resembling itself however, as for the inaqualities in the process of socio spatial distribution of the population.

Key words: Socio spatial distribution of the population. Population mobility. Functional organization of the metropolitan regions.
\end{abstract}

$\mathrm{N}$ o Brasil pós-industrialização, as migrações internas refletem processos complexos, com transformações sucessivas das áreas de atração e da natureza dos fluxos, que vão se transformando de ruralurbano para urbano-urbano.

Os movimentos migratórios internos assumiram características diferenciadas, relacionadas às diversas fases do processo de desenvolvimento brasileiro. No período 19401980 , eles foram alimentados por fortes desequilíbrios regionais e estruturaram-se para atender às necessidades de transferência regional do excedente de força de trabalho, cumprindo importante papel como mecanismo de integração social e cultural do território nacional (PACHECO; PATARRA, 1997).

Após a década de 80 , o contexto de crise e recessão contribuiu para alterar as trajetórias principais dos migrantes internos. Os movimentos de longa distância deram lugar aos de curta distância, e a trajetória rural-urbano cedeu espaço para movimentos do tipo urbano-urbano.

Entre as alterações nos movimentos migratórios, ocorridas nas últimas décadas, com impacto no processo de distribuição da população no espaço intra-urbano, destacamse: 
decréscimo nos fluxos migratórios de longa distância; intensificação da migração de retorno; consolidação da migração intrametropolitana; aumento dos movimentos migratórios intra-regionais e de curta distância; predomínio das migrações do tipo urbano-urbano; aumento dos movimentos pendulares da população (BAENINGER, 2000, p. 8).

$\mathrm{Na}$ análise sobre os movimentos do tipo urbano-urbano, é importante ressaltar a negação da associação entre mobilidade espacial e mobilidade social, que são características dos movimentos tipo rural-urbano e foram predominantes durante o período mais intenso do processo de urbanização brasileiro. As transformações na estrutura econômica, ligadas à crise e ao processo de reestruturação produtiva, introduzem a percepção sobre a noção de estratégia de sobrevivência da população como motivação para os deslocamentos intra-urbanos (BRITO, 1999).

Assim, a nova face dos movimentos migratórios internos apresenta uma tipologia de movimentos bem mais complexos que as regularidades encontradas nas migrações de longa distância.

Os deslocamentos populacionais de curta distância assumem papel preponderante na estruturação ${ }^{1}$ do espaço intra-urbano. $\mathrm{O}$ espaço nas cidades e metrópoles contemporâneas se estrutura a partir das mediações dos conflitos entre as vantagens e desvantagens, ou seja, da apropriação diferenciada da localização no espaço urbano. A otimização dos gastos com o tempo despendido nos deslocamentos intra-urbanos assume papel fundamental na geração do diferencial entre as localizações urbanas, em função das condições de acessibilidade, interferindo no processo de apropriação diferenciada das vantagens e recursos do espaço urbano. Nesse sentido, as condições de acessibilidade são decisivas para a otimização das localizações no espaço intra-urbano, constituindo-se em objeto principal dos conflitos pela posse da terra urbana (VILLAÇA, 2001).

A configuração socioespacial resultante deste processo de estruturação espacial, marcada pela formação de extensas periferias desassistidas social e economicamente, evidencia de forma indiscutível as desigualdades sociais entre segmentos populacionais do espaço intra-urbano presentes no processo de desenvolvimento nacional. Essas desigualdades são agravadas pela intensificação dos deslocamentos populacionais intra-urbanos, representados pelos fluxos migratórios intrametropolitanos em direção à periferia regional. Além disso, elas revelam a existência de uma relação de causalidade entre esses fluxos e a intensificação dos movimentos pendulares.
No caso da metrópole formada por Brasília e municípios goianos e mineiros localizados no entorno, os efeitos dessa configuração socioespacial foram definidos no âmbito do processo de exclusão e segregação espacial da população que marcou a ocupação territorial.

No período de construção e implantação, como também no período de consolidação urbana da nova capital, o Estado foi o grande promotor da ocupação do solo, atuando como planejador, construtor e financiador da ocupação, e também como grande proprietário de terras. Tornou-se, assim, o principal agente do processo de urbanização da região, o que diferencia a ocupação em relação às demais cidades brasileiras em alguns aspectos da gestão do solo urbano. ${ }^{2}$

A especificidade da atuação estatal no processo de ocupação territorial do Distrito Federal - DF deve-se mais às condições excepcionais de posse pública da terra e às possibilidades de controle sobre o uso e ocupação do solo do que à sua atuação efetiva na mediação ou atenuação dos conflitos gerados nas disputas pelo acesso à terra urbana entre os diferentes segmentos populacionais.

Sem dúvida, a questão da posse pública da terra foi um instrumento decisivo da atuação estatal no processo de ocupação urbana do DF - o que certamente não impediu as desigualdades no acesso às localizações urbanas. A questão relativa à multiplicidade de regimes de propriedade das terras ${ }^{3}$ constituiu-se em prerrogativa para a ilegalidade no acesso à terra urbana, que passou a ser utilizada como instrumento pelo mercado imobiliário, em resposta às tentativas de controle da ocupação por parte do Estado. Destarte, no período de construção e implantação do DF, o Estado manteve o monopólio sobre a terra, cabendo-lhe a decisão sobre a oferta e o parcelamento de áreas disponíveis para ocupação.

A ocupação inicial efetiva-se a partir da premissa básica que irá determinar a atuação estatal no processo de ocupação territorial: a preservação do núcleo central, formado pelo Plano Piloto. No entanto, como resposta às tentativas de controle do poder público, ao mesmo tempo em que se implantava o Plano Piloto, a pressão populacional exercida principalmente pelos operários que construíam a nova capital, obrigava o Estado a reconhecer a força dos movimentos sociais. Como resposta, formava-se a periferia, constituída pelas cidades-satélites implantadas a partir da oferta de lotes pela Companhia Urbanizadora da Nova Capital - Novacap, com o objetivo de abrigar não só o contingente de população operária migrante, mas também parte dos funcionários públicos com posições mais baixas na hi- 
erarquia funcional, sem acesso às terras localizadas no Plano Piloto.

No processo de ocupação periférica surgem inicialmente as Regiões Administrativas - RA de Taguatinga (1958), Sobradinho (1960), Gama (1960), Guará (1966) e Ceilândia (1970), inaugurando, assim, o polinucleamento característico da estruturação urbana inicial da região. Esses núcleos, denominados cidades-satélites, foram previstos no projeto urbanístico para serem implementados a partir da saturação do limite populacional estabelecido para o Plano Piloto. A antecipação de sua implantação em áreas distantes do núcleo principal gerou grandes vazios urbanos e deu início ao processo de ocupação gerenciado pela atuação pública com clara divisão social do espaço urbano.

A configuração socioespacial resultante desse processo concentra a população de renda mais elevada e maior poder político em áreas mais centrais e privilegiadas em termos de empregos, ${ }^{4}$ infra-estrutura básica e serviços sociais. Ao mesmo tempo, redistribui a população menos favorecida quanto a esses aspectos, constituindo uma ocupação periférica que se estende até os municípios limítrofes. Neles, as condições de acesso às áreas mais centrais são agravadas pelas grandes distâncias e pelas dificuldades relacionadas à eficiência do sistema de transporte (grandes vazios urbanos), implicando em intensos deslocamentos diários. ${ }^{5}$

Assim, mais do que o distanciamento físico, a reprodução do crescimento periférico gera o distanciamento social entre os segmentos populacionais que habitam os diferentes segmentos espaciais da estrutura intra-urbana.

\section{DISTRIBUIÇÃO E DINÂMICA DEMOGRÁFICA}

A Região Integrada de Desenvolvimento do Distrito Federal e Entorno - Ride é composta por uma rede de cidades que, em sua maioria, são de médio e pequeno porte. Além do DF, apenas dois municípios apresentaram população superior a 100 mil habitantes (Águas Lindas de Goiás e Luziânia), segundo o Censo Demográfico 2000. Seis outros municípios tinham população entre 50 e 100 mil (Formosa, Novo Gama, Planaltina de Goiás, Santo Antônio do Descoberto, Valparaíso de Goiás e Unaí), seis entre 20 e 50 mil habitantes (Alexânia, Cidade Ocidental, Cristalina, $\mathrm{Pa}$ dre Bernardo, Pirenópolis e Buritis) e oito municípios tinham menos de 20 mil habitantes (Abadiânia, Água Fria, Cabeceiras, Cocalzinho de Goiás, Corumbá de Goiás, Mimoso de Goiás, Vila Boa e Cabeceira Grande), sendo o menor deles Mimoso de Goiás, com apenas 2.801 habitantes. $^{6}$
A distribuição espacial da população na Ride expressa a forte polaridade exercida pelo DF, que concentrava mais de $70 \%$ da população regional, em 2000. Os municípios que apresentam as maiores participações no total da população regional são: Luziânia (4,8\%), Águas Lindas de Goiás $(3,6 \%)$ e Valparaíso de Goiás $(3,2 \%)$ - todos diretamente envolvidos no processo de expansão urbana do DF. Esta teve como principal eixo a direção Sudoeste, constituindo um entorno regional a partir das RAs e dos municípios goianos limítrofes, localizados naquela direção.

Ao longo do processo de metropolização da região, o município de Luziânia e seus desmembramentos - Cidade Ocidental, Novo Gama, Valparaíso de Goiás, Santo Antônio do Descoberto e Águas Lindas de Goiás (desmembrado de Santo Antônio do Descoberto em 1997) - , todos localizados a sudoeste do DF; e o município de Planaltina de Goiás, localizado na direção nordeste, têm-se caracterizado como o entorno mais imediato, fortemente impactado pela expansão do DF. Em conjunto com o DF, esses municípios apresentam as maiores participações no total da população regional e também as mais elevadas densidades demográficas, sendo o mais denso deles Valparaíso de Goiás, com 1.555,63 habitantes por $\mathrm{km}^{2}$.

A população da Ride é eminentemente urbana, com uma taxa de urbanização ${ }^{7}$ de 93,3\%, segundo os últimos dados censitários. Apenas três municípios apresentaram taxas de urbanização inferiores a 50,0\%: Água Fria de Goiás, Mimoso de Goiás e Cocalzinho de Goiás. Os municípios localizados no entorno imediato e o DF apresentam as maiores taxas: todas acima de $85,0 \%$.

O crescimento demográfico da Ride tem-se reduzido nas últimas décadas, apesar de apresentar uma taxa média anual de $3,5 \%$ para o período 1991/2000, considerada elevada se comparada às médias nacional ou das grandes metrópoles nacionais. ${ }^{8}$

A heterogeneidade dos municípios que compõem a Ride pode ser observada também através das estatísticas demográficas, principalmente pelo crescimento populacional e pelo processo migratório. Estes evidenciam que parte significativa do crescimento está associada à expansão do DF, uma vez que os municípios limítrofes apresentam dinâmicas diferenciadas dos demais. ${ }^{9}$

Os demais municípios não influenciados por esse processo, e que possuem como base econômica o setor agropecuário, apresentam taxas de crescimento ${ }^{10}$ e densidades demográficas ${ }^{11}$ menores. Alguns, como Pirenópolis e Mimoso de Goiás, apresentaram taxas de crescimento negativas, no período mais recente (1991-2000). 
Entre 1970 e 2000, o entorno aumentou sua participação no total da região, sendo o Entorno Imediato ${ }^{12}$ o principal responsável por esse incremento (Tabela 1). Na média, além de aumentar sua participação no total da população da Ride, o entorno apresentou elevação de 5,5\% na taxa de crescimento médio anual no último período. Apesar da redução no ritmo de crescimento do Entorno Imediato para 8,3\% no período 1991-2000, essa taxa é significativamente elevada, quando comparada à média regional.

O DF apresentou forte arrefecimento no ritmo do crescimento, principalmente em relação ao período 1970-1980, quando os fluxos migratórios dirigidos às grandes cidades foram intensificados e o processo de urbanização nacional tornou-se mais acelerado.

$\mathrm{O}$ incremento populacional da região no período total foi de 2.193.235 habitantes - 1.513.654 localizados no DFe 682.581 no entorno - sendo que, desses, 79,2\% estão localizados no entorno imediato.

\section{Principais Fluxos Migratórios ${ }^{13}$}

O estudo sobre a dinâmica migratória nacional na última década revela que algumas tendências apontadas pela dinâmica das décadas passadas concretizaram-se, tais como a recuperação da Região Sul e a perda de dinamismo das fronteiras agrícolas, com o enxugamento das áreas antigas e o surgimento de novos espaços da migração. No entanto, outras tendências não previstas puderam ser observadas. Entre elas, o incremento da emigração nordestina, apesar das transformações produtivas que sugeriam um arrefecimento desses fluxos, e a intensificação dos processos redistributivos no interior das regiões metropolitanas consolidadas (BAENINGER, 2004).
Na última década, a região de Brasília e entorno - a exemplo da dinâmica migratória de outras metrópoles nacionais - apresentou tendência de incremento da imigração de nordestinos que se dirigiram prioritariamente para o $\mathrm{DF}$ e, numa escala menor, para os municípios do entorno. Além disso, houve intenso processo redistributivo interno, fortemente determinado pela emigração originária do DF, em direção aos municípios do entorno metropolitano.

Os municípios que compõem a Ride apresentam dinâmicas migratórias diferenciadas. A análise dos Índices de Eficácia Migratória - IEM ${ }^{14}$ para a migração interestadual revela que alguns municípios são absorvedores líquidos de população, enquanto outros assumem características de áreas de evasão populacional, ainda que essas localidades apresentem tendência à reversão desse quadro.

Entre 1975 e 2000, o Distrito Federal consolidou-se como área de rotatividade migratória, apresentando valores semelhantes nos volumes de imigração e emigração. Esse fato está relacionado à capacidade de atração da capital federal e ao processo de redistribuição desses imigrantes para os demais municípios da região. No final do período, a maioria dos municípios registrou índices que os caracterizam como áreas de forte absorção migratória, com IEM entre 0,51 e 1,00 .

A Ride, estruturada a partir de uma cidade planejada para ser a capital nacional e pólo de integração nacional, teve seu processo de consolidação como metrópole marcado pela migração de longa distância, principalmente durante as décadas de 60 e 70 . Fatores associados à abertura de frentes de trabalho para a construção da cidade e à transferência da capital fizeram com que a migração interestadual fosse predominante no processo de implantação da nova cidade.

TABELA 1

Evolução da População e Taxas de Crescimento Região Integrada de Desenvolvimento do Distrito Federal e Entorno - 1970-2000

\begin{tabular}{|c|c|c|c|c|c|c|c|c|c|c|c|}
\hline \multirow{2}{*}{ Região } & \multicolumn{4}{|c|}{ Números Absolutos } & \multicolumn{4}{|c|}{ Participação (\%) } & \multicolumn{3}{|c|}{ Taxas de Crescimento (\% a.a.) } \\
\hline & 1970 & 1980 & 1991 & 2000 & 1970 & 1980 & 1991 & 2000 & $1970-1980$ & $1980-1991$ & $1991-2000$ \\
\hline Total da Ride & 761.961 & 1.519 .981 & 2.161 .709 & 2.958 .196 & 100,00 & 100,00 & 100,00 & 100,00 & 7,15 & 3,25 & 3,55 \\
\hline Brasília & 537.492 & 1.176 .908 & 1.601 .094 & 2.051 .146 & 70,54 & 77,43 & 74,13 & 69,47 & 8,15 & 2,84 & 2,79 \\
\hline Total Entorno & 224.469 & 343.073 & 560.615 & 907.050 & 29,46 & 22,57 & 25,87 & 30,53 & 4,33 & 4,57 & 5,49 \\
\hline Entorno Imediato (1) & 40.971 & 107.530 & 283.384 & 582.056 & 5,38 & 7,07 & 13,06 & 19,72 & 10,13 & 9,21 & 8,33 \\
\hline Demais Municípios & 183.498 & 235.543 & 277.231 & 324.994 & 24,08 & 15,50 & 12,81 & 10,81 & 2,53 & 1,49 & 1,78 \\
\hline
\end{tabular}

Fonte: IBGE. Censos Demográficos 1970, 1980, 1991 e 2000.

(1) 0 entorno imediato é formado pelos municípios de Águas Lindas de Goiás, Cidade Ocidental, Luziânia, Novo Gama, Planaltina de Goiás, Santo Antônio do Descoberto e Valparaíso de Goiás. 
O processo de formação e consolidação da Ride, na década de 80 , foi fortemente influenciado pela expansão da mancha urbana do DF. Os movimentos migratórios regionais confirmam esse processo, no qual a migração intrametropolitana ${ }^{15}$ adquire expressão no total dos fluxos migratórios, ainda que os fluxos interestaduais continuem predominantes.

Desde o início do processo de migração para Brasília, os fluxos de nordestinos, goianos e mineiros foram predominantes. ${ }^{16}$ Além da atratividade exercida pela existência de grande número de empregos durante a construção da capital, a condição de vida naqueles Estados contribuiu para a consolidação dos fluxos. Holston (1993), baseado em informações do Censo Demográfico 1960, aponta que 96,0\% dos migrantes vindos para Brasília vinham daquelas regiões (de Estados do Nordeste; do Sudeste, principalmente de Minas Gerais; e do Centro-Oeste, principalmente de Goiás). ${ }^{17}$ Segundo aquele autor, a migração, já naquele período, era predominantemente urbana, sendo que quatro em cada cinco migrantes residiam anteriormente em área urbana.

Entre 1970 e 1980, período de maior dinamismo do processo de urbanização da região, os principais fluxos da migração interestadual continuaram sendo aqueles originados em Estados nordestinos (212 mil), em Goiás (167 mil) e em Minas Gerais (90 mil). Entre os Estados nordestinos, destacam-se os fluxos vindos do Maranhão, Piauí, Ceará e Bahia, que apresentaram, em conjunto, o maior volume (155 mil migrantes).

Entre 1981 e 1991, o volume de migrantes arrefeceu $(605,8$ mil), mas a taxa de migração ${ }^{18}$ permaneceu expressiva $(3,04 \%)$. O fluxo de nordestinos continuou elevado (207,7 mil) e os Estados que mais contribuíram para esse movimento (MA, PI, CE e BA) enviaram, em conjunto, 157,8 mil migrantes - contingente maior que o do período anterior. Maior, também, foi o contingente vindo das Regiões Norte e Sul - o que demonstrava a ampliação da atratividade exercida pela capital federal. A situação se mantém no período 1991-2000, e os fluxos originados nos quatro Estados nordestinos (MA, PI, CE e BA) e na Região Norte ampliam-se ainda mais.

O fluxo de migrantes com residência anterior no DF cresceu significativamente, passando de 49 mil, entre 1970 e 1980, para 121,6 mil no período 1981-9; e para 136,7, entre 1990 e 2000 - fato que denotou ampliação do fluxo migratório intra-regional. Em síntese, a Ride caracteriza-se pelo predomínio de migrantes provenientes principalmente dos Estados do Maranhão, Piauí, Ceará e Bahia, cuja taxa média anual de migração ainda é a mais elevada na região
(1,44\%, no período 1970-1980; e 0,86\%, entre 1990 e 2000). É importante salientar que, a exemplo do ocorrido no DF, apesar da tendência de queda da taxa para o total da região ao longo do período 1970-2000, a imigração originária daqueles Estados nordestinos apresentou elevação no período mais recente, enquanto os demais fluxos registraram redução ou mantiveram constantes as taxas médias anuais de migração interestadual.

Além de apresentar elevação, a migração originária daqueles Estados nordestinos manteve-se, e como o fluxo mais importante ao longo do período. Isto indica a provável existência de redes sociais de migração atuando nesse fluxo e mantendo-o com relativa intensidade, apesar do arrefecimento das migrações no país e na região, nos períodos mais recentes.

O fluxo originário do DF apresentou elevação na década de 80 - período de consolidação do processo de crescimento periférico em direção aos municípios goianos. Apesar de ligeira queda no período mais recente, ele ainda se mantém como o segundo fluxo de migração para o total da região.

De 1970 a 1980, quando o processo de crescimento periférico ainda era incipiente, a participação dos fluxos vindos do DF representava $7,7 \%$ do total, enquanto o fluxo total de nordestinos para a região respondia por $33,5 \%$. No período 1981-1991, quando o crescimento dos municípios goianos intensificou-se e o entorno regional se consolidou, a participação dos fluxos originários do DF passou a representar 20,3\% do total e a de nordestinos se manteve (34,7\%). Entre 1990 e 2000, a migração de nordestinos e a vinda do DF aumentaram suas participações para $41,6 \% \mathrm{e}$ 22,0\%, respectivamente (Gráfico 1).

Quando analisado todo o período (1970-2000), observa-se que os fluxos migratórios originários nos demais Estados do Nordeste diminuíram; e aqueles provenientes de Minas Gerais, Goiás e demais Estados do Sudeste, que foram bastante significativos no período inicial, perderam intensidade.

A partir da década de 80, o Distrito Federal passou a expulsar população para os demais municípios da região, elevando a participação da migração para o total da região, enquanto os demais fluxos sofreram retração.

Na verdade, os volumes de migrantes interestaduais para a região demonstram seu grande peso, devido aos fluxos direcionados ao DF. Houve redução nos fluxos de mineiros e goianos ao longo do período - a exemplo do ocorrido para o total de região - e manutenção do volume de migrantes nordestinos, apesar da redução dos volumes 


\section{GRÁFICO 1 \\ Participação da Imigração Interestadual \\ Região Integrada de Desenvolvimento do Distrito Federal \\ e Entorno - 1970-2000}
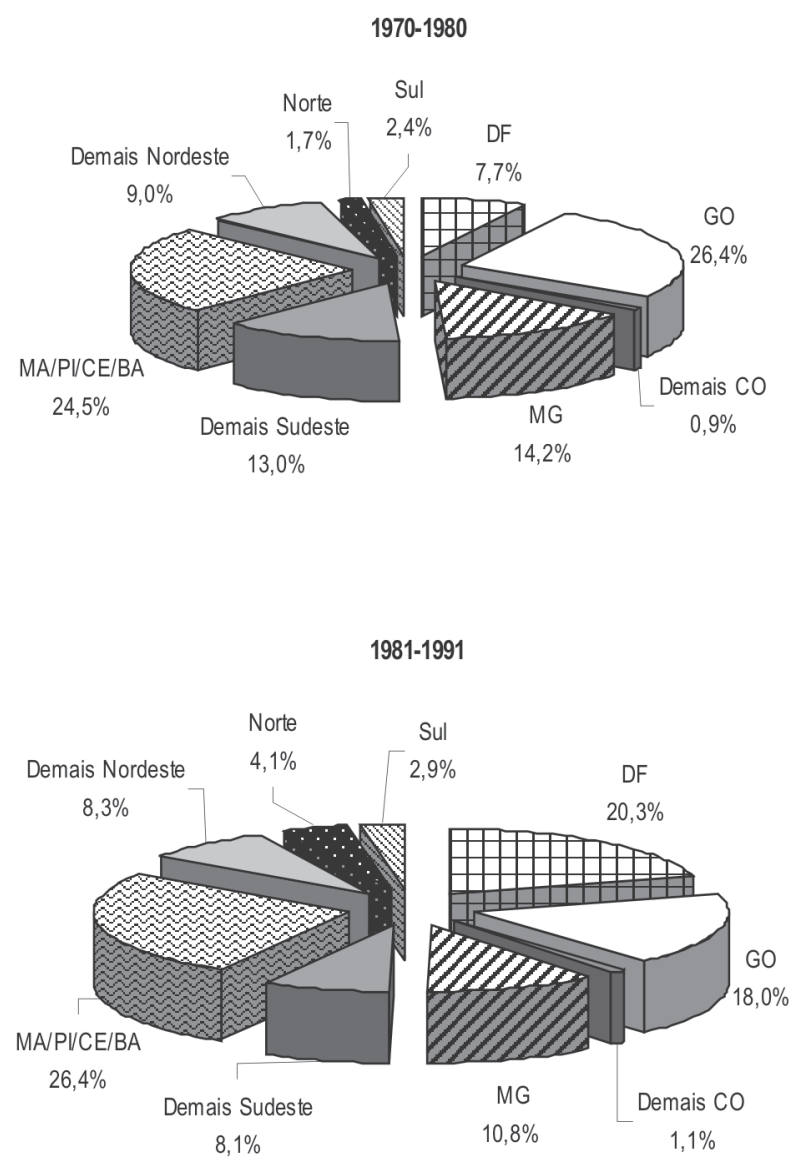

$1990-2000$

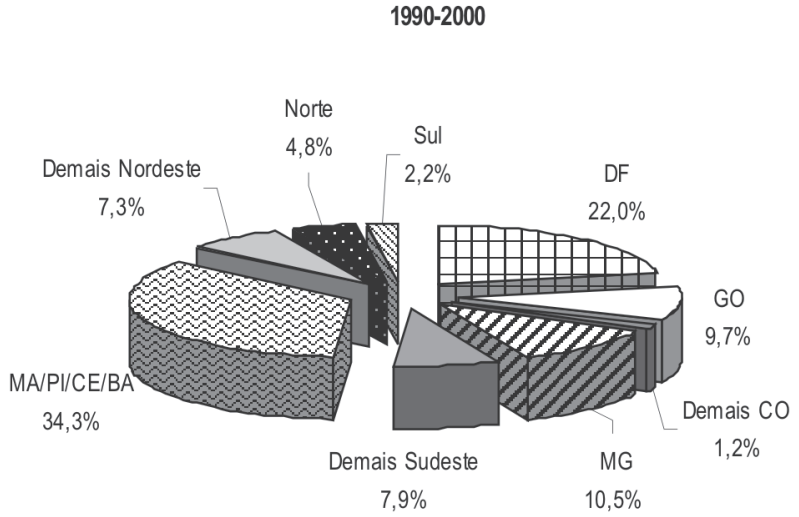

Fonte: IBGE. Censos Demográficos 1980, 1991 e 2000 (tabulações especiais do Nepol Unicamp). totais de imigrantes. Na última década, a elevação do fluxo de Maranhão, Piauí, Ceará e Bahia retoma a importância em relação à década de 70, período de maior intensidade migratória nos contextos regional e nacional (Tabela 2).

A distribuição da migração interestadual para o total da região é semelhante à do Distrito Federal, em função do peso que aquela população assume no total regional (em torno de $70,0 \%$, desde 1970 até 2000).

A Tabela 3 mostra duas tendências em relação ao fluxo de migrantes nordestinos para a região. Ao longo do período 1970-2000, o peso da migração de nordestinos para o DF diminui, passando de $95,1 \%$ entre 1970 e 1980 para $41,5 \%$ de 1990 a 2000, aumentando a participação desse fluxo na migração interestadual para o total da região.

Outra tendência observada nesse fluxo é a elevação da participação de Maranhão, Piauí, Ceará e Bahia no total da migração de nordestinos para o total da região.

Na verdade, essa elevação da participação está relacionada ao aumento do fluxo em direção aos municípios que integram o entorno imediato da Ride. Os volumes médios anuais da migração para os municípios elevaram-se de 455 , no período 1970-1980, para 5.556, entre 1990 e 2000 (Tabela 4).

A migração vinda do DF, no período inicial (1970-1980), já apresentava participações elevadas no total da migração interestadual de vários municípios. Além dos municípios que integram o entorno imediato (naquele período, Planaltina e Luziânia), outros como Alexânia, Corumbá de Goiás, Formosa, Padre Bernardo e Pirenópolis tinham nos fluxos vindos do DF a maior participação na migração entre UFs - embora os volumes de população migrante sejam numericamente pouco significativos. Naqueles municípios, o segundo principal fluxo vem de municípios mineiros que não integram a Ride. Como eles apresentam base econômica na agropecuária, é possível que a migração de mineiros tenha sido motivada pela expansão da fronteira agrícola ocorrida na região (aumento do plantio de soja no serrado, naquele período).

A migração de nordestinos para outras regiões do país tem sido bastante estudada. No entanto, os dados sobre naturalidade e local de residência anterior dos imigrantes que chegam à Ride possibilitam uma visão mais ampla do fenômeno da re-migração da população originária dos Estados nordestinos, e indicam, principalmente, a não-absorção de parte desse contingente de imigrantes pelo DF. No período 1986-1991, o fluxo de migrantes vindo do DF para o entorno era composto de 51,8\% de naturais dos Estados do Nordeste, dos quais 38,1\% nascidos no Maranhão, 
TABELA 2

Volume e Taxa Média Anual de Migração Interestadual, segundo Região de Última Residência Região Integrada de Desenvolvimento do Distrito Federal e Entorno - 1970-2000

\begin{tabular}{|c|c|c|c|c|c|c|}
\hline \multirow{2}{*}{$\begin{array}{l}\text { Região de Residência } \\
\text { Anterior }\end{array}$} & \multicolumn{2}{|c|}{$1970-1980$} & \multicolumn{2}{|c|}{$1981-1991$} & \multicolumn{2}{|c|}{$1990-2000$} \\
\hline & Volume & Taxa (\%) & Volume & Taxa (\%) & Volume & Taxa $(\%)$ \\
\hline Total da Ride & 483.212 & 3,52 & 354.917 & 2,35 & 378.304 & 2,51 \\
\hline Goiás & 88.468 & 0,64 & 53.433 & 0,35 & 58.225 & 0,39 \\
\hline Outros do Centro-Oeste & 4.956 & 0,04 & 4.698 & 0,03 & 5.921 & 0,04 \\
\hline Minas Gerais & 77.518 & 0,56 & 49.048 & 0,32 & 47.608 & 0,32 \\
\hline Rio de Janeiro & 53.404 & 0,39 & 22.856 & 0,15 & 19.086 & 0,13 \\
\hline Outros do Sudeste & 25.962 & 0,19 & 17.097 & 0,11 & 20.772 & 0,14 \\
\hline $\mathrm{MA} / \mathrm{PI} / \mathrm{CE} / \mathrm{BA}$ & 147.425 & 1,07 & 129.653 & 0,86 & 153.363 & 1,02 \\
\hline Outros do Nordeste & 53.281 & 0,39 & 40.774 & 0,27 & 33.001 & 0,22 \\
\hline Região Norte & 10.467 & 0,08 & 20.778 & 0,14 & 22.492 & 0,15 \\
\hline Região Sul & 14.326 & 0,10 & 10.850 & 0,07 & 10.723 & 0,07 \\
\hline Outros & 7.405 & 0,05 & 5.730 & 0,04 & 7.113 & 0,05 \\
\hline
\end{tabular}

Fonte: IBGE. Censos Demográficos 1980, 1991 e 2000 (tabulações especiais do Nepo/Unicamp).

Nota: Foram consideradas migrantes as pessoas com mais de dez anos de idade e com menos de dez anos de residência na UF, incluindo a migração de retorno e os não-naturais.

TABELA 3

Migração de Nordestinos, segundo Local de Residência Atual

Região Integrada de Desenvolvimento do Distrito Federal e Entorno - 1970-2000

\begin{tabular}{|c|c|c|c|c|c|c|c|c|c|}
\hline \multirow{2}{*}{ Local de Residência Atual } & \multicolumn{2}{|c|}{$1970-1980$} & \multicolumn{2}{|c|}{$1981-1991$} & \multicolumn{2}{|c|}{$1990-2000$} & \multicolumn{3}{|c|}{ Média Anual } \\
\hline & $\mathrm{N}^{\mathrm{os}}$ Abs. & $\%$ & Nos Abs. & $\%$ & $\mathrm{~N}^{\circ \mathrm{s}}$ Abs. & $\%$ & $1970-1980$ & 1981-1991 & $1990-2000$ \\
\hline \multicolumn{10}{|l|}{ Distrito Federal } \\
\hline Migrantes de MA/PI/CE/BA & 147.425 & 95,1 & 129.653 & 82,3 & 153.363 & 41,5 & 14.743 & 12.965 & 15.336 \\
\hline Total de Nordestinos & 200.706 & 94,7 & 170.427 & 82,8 & 186.364 & 41,0 & 20.071 & 17.043 & 18.636 \\
\hline \multicolumn{10}{|l|}{ Total da Ride } \\
\hline Migrantes de MA/PI/CE/BA & 155.014 & 73,0 & 157.457 & 75,6 & 369.119 & 81,3 & 15.501 & 15.746 & 36.912 \\
\hline Total de Nordestinos & 212.015 & 100,0 & 205.848 & 100,0 & 454.013 & 100,0 & 21.201 & 20.585 & 45.401 \\
\hline
\end{tabular}

Fonte: IBGE. Censos Demográficos 1980, 1991 e 2000 (tabulações especiais do Nepo/Unicamp).

Nota: Foram consideradas migrantes as pessoas com mais de dez anos de idade e com menos de dez anos de residência na UF, incluindo a migração de retorno e os não-naturais.

\section{TABELA 4}

Principais Volumes de Migração de Nordestinos para o Entorno Imediato, segundo Local de Residência Atual Região Integrada de Desenvolvimento do Distrito Federal e Entorno - 1970-2000

\begin{tabular}{|c|c|c|c|c|c|c|c|c|c|}
\hline \multirow{2}{*}{ Local de Residência Atual } & \multicolumn{2}{|c|}{$1970-1980$} & \multicolumn{2}{|c|}{$1981-1991$} & \multicolumn{2}{|c|}{$1990-2000$} & \multicolumn{3}{|c|}{ Média Anual } \\
\hline & Nos Abs. & $\%$ & Nos Abs. & $\%$ & $\mathrm{~N}^{\mathrm{os}}$ Abs. & $\%$ & $1970-1980$ & $1981-1991$ & $1990-2000$ \\
\hline \multicolumn{10}{|l|}{ Luziânia (1) } \\
\hline Migrantes de MA/PI/CE/BA & 4.226 & 71,1 & 14.523 & 76,6 & 30.867 & 82,0 & 423 & 1.452 & 3.087 \\
\hline Total de Nordestinos & 5.944 & 100,0 & 18.956 & 100,0 & 37.659 & 100,0 & 594 & 1.896 & 3.766 \\
\hline \multicolumn{10}{|l|}{ Planaltina de Goiás } \\
\hline Migrantes de MA/PI/CE/BA & 319 & 53,5 & 2.897 & 76,2 & 6.735 & 82,4 & 32 & 290 & 674 \\
\hline Total de Nordestinos & 596 & 100,0 & 3.800 & 100,0 & 8.176 & 100,0 & 60 & 380 & 818 \\
\hline \multicolumn{10}{|c|}{ Santo Antônio do Descoberto (1) } \\
\hline Migrantes de MA/PI/CE/BA & - & - & 3.393 & - & 17.954 & - & - & 339 & 1.795 \\
\hline Total de Nordestinos & - & - & 4.528 & - & 20.531 & - & - & 453 & 2.053 \\
\hline \multicolumn{10}{|l|}{ Total Entorno Imediato } \\
\hline Migrantes de MA/PI/CE/BA & 4.545 & 69,5 & 20.813 & 76,3 & 55.556 & 83,7 & 455 & 2.081 & 5.556 \\
\hline Total de Nordestinos & 6.540 & 100,0 & 27.284 & 100,0 & 66.366 & 100,0 & 654 & 2.728 & 6.637 \\
\hline
\end{tabular}

Fonte: IBGE. Censos Demográficos 1980, 1991 e 2000 (tabulações especiais do Nepo/Unicamp).

(1) Desconsiderados os desmembramentos de 1997.

Nota: Foram consideradas migrantes as pessoas com mais de dez anos de idade e com menos de dez anos de residência na UF, incluindo a migração de retorno e os não-naturais. 
Piauí, Ceará ou Bahia. No período mais recente (1995-2000), a população natural desses Estados representou 49,8\% do fluxo de migrantes do DF em direção a outros municípios da Ride.

\section{Deslocamentos Intra-urbanos e Consolidação da Expansão Urbana no Entorno Regional}

A migração interestadual teve papel preponderante na formação do entorno, uma vez que foi responsável por grande parte do incremento populacional do DF (principalmente nas décadas de 70 e 80 , quando ocorreu a intensificação do processo de periferização), o que potencializou o processo de redistribuição para os municípios do Entorno Imediato.

No caso da Ride, a mobilidade intra-urbana teve como principal elemento definidor da intensidade e direção dos fluxos a busca por moradias dos segmentos populacionais que ocupam posições menos privilegiadas na estrutura social, em áreas onde existe menor pressão para ocupação por parte dos segmentos de rendas mais elevadas, que conseguem se apropriar das localizações urbanas otimizadas, com acessibilidade ao centro e atividades socioeconômicas privilegiadas.

Os instrumentos utilizados para viabilizar a apropriação diferenciada das acessibilidades eram fruto, principalmente, da atuação do Estado. Este utilizou os mecanismos de controle do uso e ocupação do solo, sob a prerrogativa da preservação do meio-ambiente. E também, no caso do DF, valeu-se da preservação do projeto arquitetônico e paisagístico do Plano Piloto - ambos associados à política habitacional que conduziu à ocupação periférica.

Além da atuação estatal, o mercado imobiliário também teve papel fundamental na estruturação da Ride, principalmente no que se referiu à ocupação do entorno do quadrilátero, constituída por municípios goianos limítrofes. Para tanto, atuou nas lacunas deixadas pela ação estatal na oferta de moradias para a população de baixa renda.

Esses condicionantes da estruturação intra-urbana funcionaram como uma estrutura de pressões ou motivações, e atuaram tanto nos lugares de destino como nos de origem. Assim, levaram a população a se deslocar no espaço intra-urbano e estabeleceram trocas entre municípios da região (CUNHA, 1994).

A não-absorção de grande parte do contingente migratório com destino ao DF fez com que a migração intrametropolitana ganhasse importância relativa no total dos migrantes que chegam à região, impactando a expansão do entorno regional. A participação dos migrantes internos à região ampliou-se: de $15,7 \%$ para $28,0 \%$ do total, ao longo do período 1975-2000.

Essa elevação deu-se não só pelo aumento de volume de migrantes intrametropolitanos - que passaram de 66.584 para 119.769, no período 1975-2000 - mas também em função da redução da chegada de migrantes vindos dos demais municípios de Goiás e Minas Gerais. A elevação da participação da emigração do DF em direção aos municípios da região, inclusive os que não integram o Entorno Imediato, reduziu as participações das migrações entre municípios vizinhos que até então predominavam naqueles não diretamente envolvidos no processo de expansão urbana, indicando a intensificação das relações entre o DF e o Entorno Distante.

As participações das imigrações segundo o local de origem e de destino se alteraram ao longo do período 19752000. Os dados desagregados para os três recortes espaciais demonstraram que a elevação da participação da migração intrametropolitana pode ser atribuída à sua elevação para os municípios do entorno que não integram o Entorno Imediato (Gráfico 2).

Como já foi dito, o fluxo de migração intrametropolitana mais significativo foi representado pelos que deixam o DF em direção ao Entorno Imediato. No período 1975-1980, 33.866 pessoas deixaram o DF para municípios que integram este recorte, principalmente para os localizados no sudoeste da Ride (Santo Antônio do Descoberto, Luziânia e seus desmembramentos: Águas Lindas de Goiás, Cidade Ocidental, Novo Gama e Valparaíso de Goiás). Nos períodos seguintes, os volumes desse fluxo se elevaram para 46.162 (1986-1991) e 80.942 (1995-2000).

Nos demais municípios do entorno, ocorreu a redução da imigração vinda dos outros municípios vizinhos e foi aumentada a participação da migração vinda do DF e dos municípios do Entorno Imediato. Outra tendência observada para o período foi a intensificação das trocas entre municípios do Entorno Imediato e os demais da região.

Para os três recortes espaciais, foi possível observar a elevação da participação da migração vinda de municípios do Entorno Imediato (ainda que os números sejam pouco expressivos), indicando um novo aspecto da redistribuição populacional na região, associado à capacidade de absorver população por parte daqueles municípios.

Nas trocas populacionais intra-regionais, foram significativos apenas os fluxos representados pela emigração do DF em direção aos municípios que integram o Entorno Imediato - ainda que fosse possível identificar outras ten- 


\section{GRÁFICO 2}

Evolução da Migração Intrametropolitana

Região Integrada de Desenvolvimento do Distrito Federal e Entorno - 1975-2000
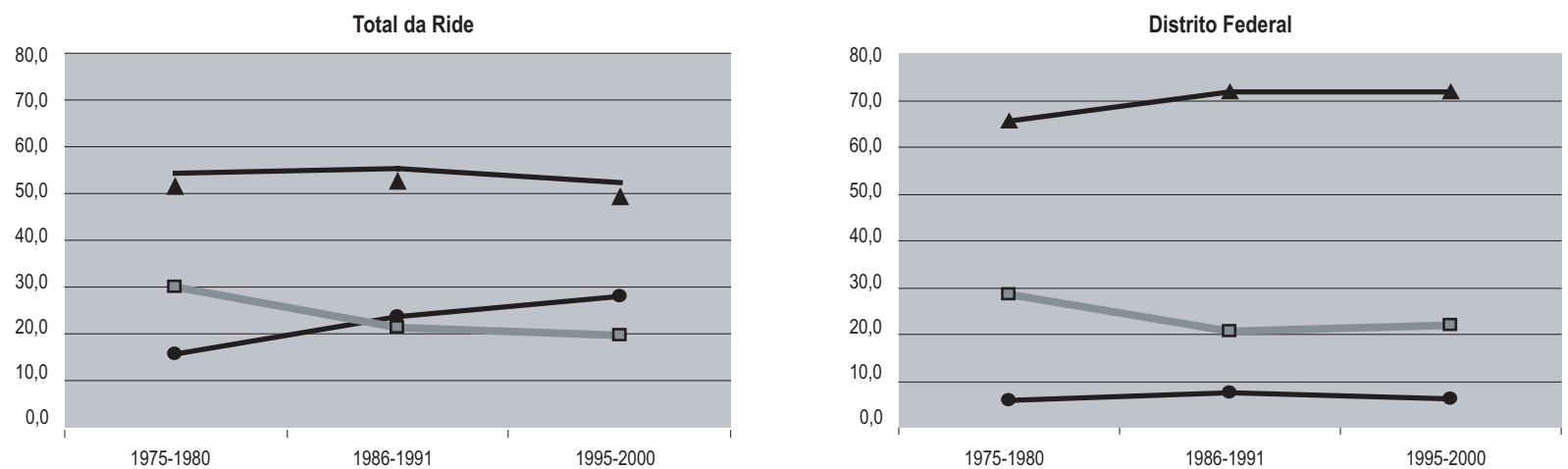

Entorno Imediato

Entorno Distante
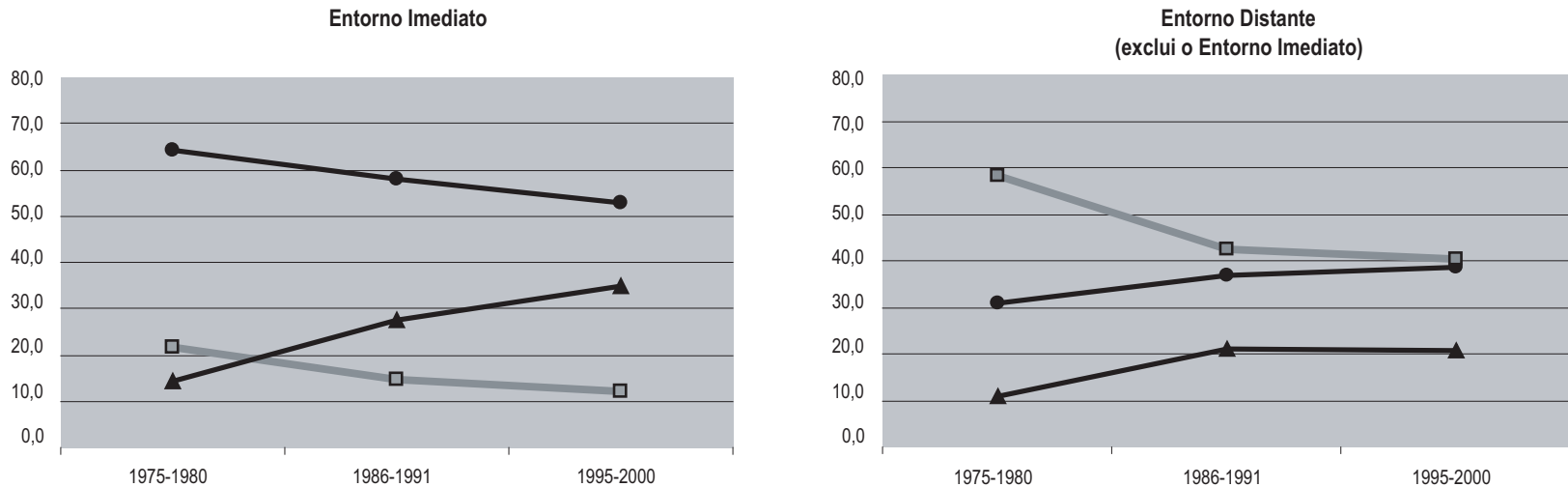

$\rightarrow$ Intrametropolitana

- Interestadual GO e MG

$\rightarrow$ - Interestaduais

Fonte: IBGE. Censos Demográficos 1980, 1991 e 2000 (tabulações especiais do Nepo/Unicamp).

dências redistributivas de população no interior da Ride (Mapa 1).

No período mais recente (1995-2000), saíram de Brasília 78.002 habitantes, enquanto no Entorno Imediato entraram 75.257 - destes, 34.907 passaram a residir em Águas Lindas de Goiás.

Apesar da participação da migração vinda do DF para os municípios do Entorno Imediato ter apresentado ligeira queda na emigração intrametropolitana, isto não significa redução, mas sim ampliação das trocas entre municípios desse recorte espacial. Tanto a participação quanto o número de pessoas que deixam o DF em direção ao entorno continuaram apresentando elevação no período mais recente. Dos 89.376 emigrantes intra-regionais que deixaram no DF no período $1995-2000,90,6 \%$ dirigiram-se para aqueles municípios.

No período 1995-2000, intensificou-se a migração em direção aos demais municípios da região, até então não diretamente envolvidos no processo de expansão periférica. As trocas entre municípios do Entorno Imediato também apresentaram elevação, indicando que suas inter-relações ganham intensidade. Isso se dá pela melhora em suas dinâmicas econômicas e pelo processo de valorização imobiliária, em função das melhorias em infra-estrutura. 


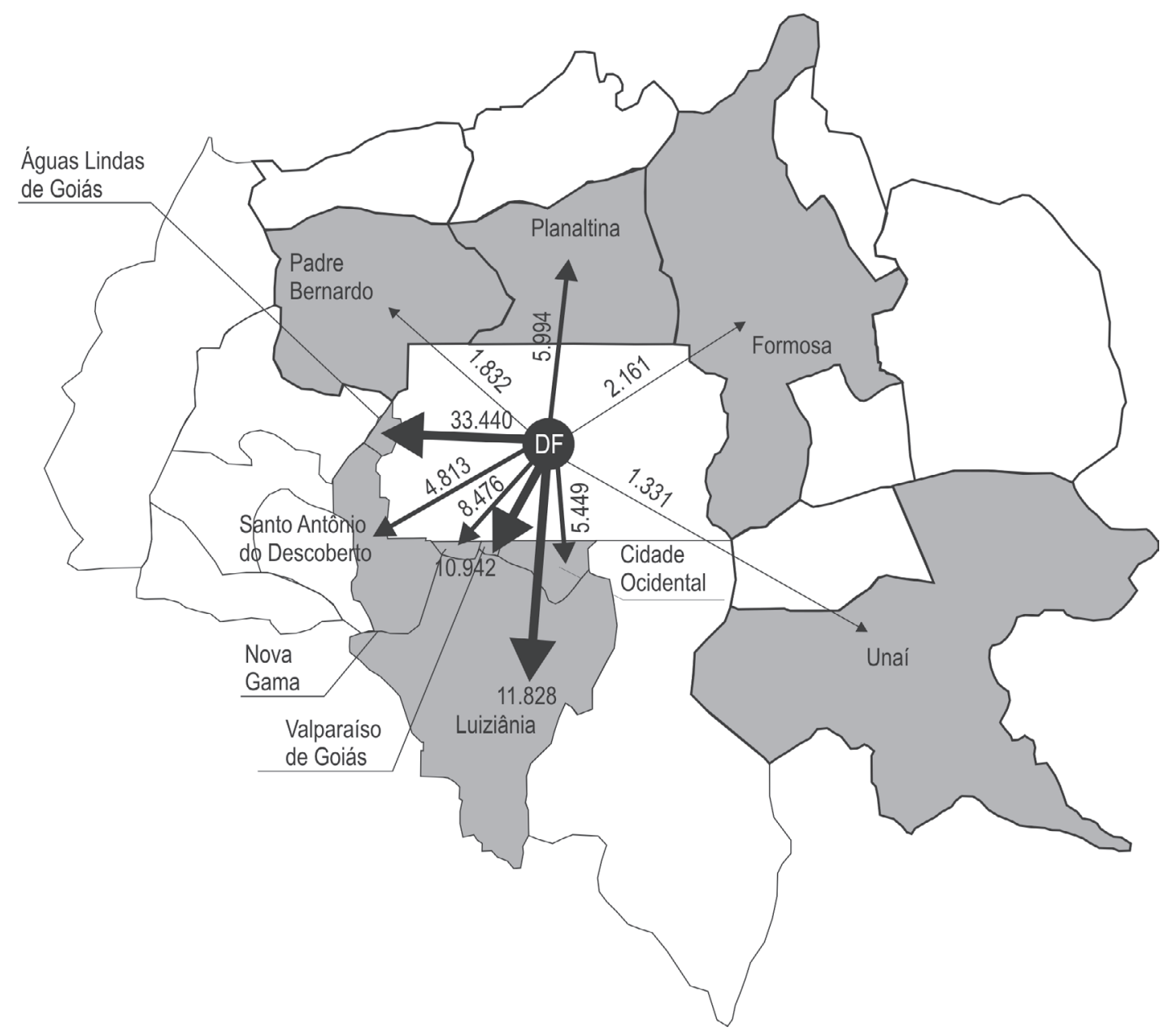

Fonte: IBGE. Censos Demográficos 1980, 1991 e 2000 (tabulações especiais do Nepo/Unicamp).

Migração Intrametropolitana e Mobilidade Pendular - A mobilidade pendular apresenta estreita relação com o processo de estruturação urbana: principalmente no que se refere aos diferenciais entre as localizações das atividades no espaço urbano regional e a intensificação da migração intrametropolitana. No processo de estruturação intra-urbana, a necessidade de deslocamento de pessoas em direção ao entorno (migração intrametropolitana) certamente gerou a intensificação desses fluxos pendulares, na busca pelo atendimento das demandas por emprego e/ou atividades geradoras de renda para essa população que não consegue inserir-se no espaço do DF. A ligação entre os dois tipos de movimentos populacionais é estreita: a ocorrência do primeiro gera a do segundo. Ou seja, ao se mudar para o entorno, a população passa a depender das viagens diárias em direção ao antigo local de moradia, como forma de obter renda e serviços que lhe permitam sobreviver.

$\mathrm{O}$ volume de pessoas que se movem diariamente no interior da Ride cresce de 13.328 em 1980, para 132.909 no ano de $2000 .{ }^{19}$ Das 132.914 pessoas que se movem diariamente no interior da região, $119.916(90,2 \%)$ deixam municípios localizados no Entorno Imediato em direção ao Distrito Federal, onde estão concentrados os empregos e as atividades que possibilitam geração de renda. 
A intensidade e a direção da mobilidade pendular na Ride revelam os diferenciais no acesso ao solo urbano pelos diferentes segmentos sociais da população, implicando em deslocamento na busca pelo atendimento das demandas básicas por trabalho, serviços sociais, lazer e atividades de consumo, com o agravamento gerado pelas grandes distâncias e pelo deficiente sistema de transportes.

Entre estes, a demanda por trabalho ou educação, além de assumir peso maior entre as demais em função do seu caráter de movimentação diária, pode ser mensurada a partir dos dados censitários, estabelecendo diferenciais entre as pessoas que realizam mobilidade pendular, segundo sua condição migratória e residência anterior.

Grande parte da população que realiza movimentos pendulares já realizou algum movimento migratório em direção ao atual município de residência. Cerca de $42,4 \%$ do total das pessoas que realizavam movimentos pendulares em 2000 tinham menos de cinco anos de residência no município em que residiam; e, destas, 50,3\% declararam como residência, em 31/7/1995, o Distrito Federal. Assim, fica confirmada a estreita ligação entre migração intrametropolitana, processo de periferização e intensificação dos deslocamentos diários.

Desagregados para os diferentes recortes espaciais, os dados revelam que $58,5 \%$ das pessoas que realizam movimentos pendulares residem no Entorno Imediato; e as que residiam a menos de cinco anos no município vieram do DF.

No entanto, se comparamos com os dados de 1980, podemos observar que o porcentual de pessoas que realizam movimentos diários em direção a Brasília, que residem no Entorno Imediato e declaram residência anterior no Distrito Federal caiu de 72,3\%, em 1980, para 59,3, em 2000. Essa redução do peso dos emigrantes do DF em relação às pessoas que realizam a mobilidade pendular ocorre em função da elevação da participação dos fluxos interestaduais no total da migração em direção ao Entorno Imediato.

Apesar de o Distrito Federal continuar concentrando as oportunidades de emprego e geração de renda, os municípios do Entorno Imediato - principalmente Novo Gama, Cidade Ocidental e Valparaíso de Goiás - vêm aumentando sua participação como receptores de pessoas que realizam mobilidade pendular. Eles recebem $32 \%$ das pessoas residentes em Brasília que realizam este movimento: mais especificamente nas Regiões Administrativas do Gama e de Santa Maria, cujas distâncias são menores em direção a esses municípios do que em direção às regiões onde se concentram os empregos no DF (como o setor comercial sul no Plano Piloto ou o centro da Região Administrativa de Taguatinga, por exemplo).

\section{CONSIDERAÇÕES FINAIS}

O objetivo deste texto foi contribuir para o estabelecimento de relações entre o processo de estruturação intraurbana e os deslocamentos intra-urbanos, na região metropolitana formada pelo DF e municípios goianos e mineiros do entorno.

Entre as grandes cidades e metrópoles nacionais, Brasília destaca-se não tanto pelas especificidades relacionadas ao seu processo de criação e construção, mas principalmente pelas possibilidades de gestão urbana geradas pela quase inexistência de antecedentes relacionados à ocupação territorial urbana, e pela propriedade pública de grande parte da terra destinada à nova capital.

No decorrer de seu processo de construção e consolidação, Brasília tornou visíveis as contradições inerentes à organização social brasileira: passou de cidade que pretendia ser socializante na distribuição de pessoas e atividades para uma estrutura intra-urbana fortemente marcada pelo processo de segregação socioespacial da população. Ao invés de constituir-se em um instrumento distributivo, a propriedade pública da terra urbana passa a funcionar como instrumento de ocupação seletiva, instituindo a "segregação planejada" e transformando Brasília na "capital do controle e da segregação social". ${ }^{20}$

Outra especificidade da estrutura intra-urbana na região é a ausência da conurbação entre as localidades periféricas. Este fato deu origem a uma estrutura fragmentada, composta por vários núcleos de ocupação urbana, separados por grandes glebas sem ocupação - o que torna ainda mais distantes as localidades periféricas, e mais difíceis as condições de deslocamento da população residente nesse segmento espacial.

Evidentemente, apesar das especificidades, o processo de estruturação urbana e distribuição populacional do Distrito Federal e entorno não pode ser dissociado dos processos de urbanização e desenvolvimento nacional. A configuração socioespacial resultante do processo de urbanização não poderia ser muito diferente daquelas encontradas nas demais metrópoles nacionais, uma vez que está submetida ao mesmo processo econômico (regime de acumulação) e à mesma formação social.

A análise sobre os dados dos deslocamentos intra-urbanos demonstrou a estreita relação entre intensificação dos fluxos e crescimento periférico, e à existência de uma relação de causalidade entre a migração intra-urbana e a intensificação dos movimentos pendulares. A análise dos dados sobre os deslocamentos intra-urbanos diários indi- 
cou que $42,4 \%$ das pessoas que realizavam movimentos pendulares residiam há menos de cinco anos no município - destas, 50,3\% declararam como residência anterior o Distrito Federal.

A possibilidade de gestão urbana integrada que a definição da Ride traz certamente será um importante instrumento para a amenização dos problemas atuais. Entre as contradições a serem enfrentadas pela gestão urbana na região destacam-se a questão dos conflitos gerados pela propriedade da terra destinada ao uso urbano e a ilegalidade na ocupação intra-urbana.

O não atendimento da inesgotável demanda por moradias, gerada pelo crescimento urbano, que, apesar do arrefecimento na década de 80 , deu indícios de novo dinamismo nos anos 90, inclusive em função da manutenção da intensidade dos fluxos migratórios para a região nessa última década, gera novas ocupações em áreas centrais, demandando soluções que não alimentem o crescimento periférico.

A questão do emprego assume particularidades que agravam o processo de exclusão da população periférica. A economia regional baseia-se nas transferências de rendas, conformando um grande mercado consumidor. A elevada renda que potencializa esse mercado consumidor não provém de uma inserção produtiva regional, mas sim da ocupação de parte da população na administração pública, gerada em função dos altos salários pagos ao funcionalismo federal.

A evolução crescente do desemprego na região tem evidenciado a insuficiência da economia local na geração de empregos. O crescimento populacional - mais especificamente a expansão da população economicamente ativa - PEA - associado à retração na oferta de postos de trabalho, vem-se traduzindo num quadro social problemático, com tendências agravantes. ${ }^{21}$

Nesse sentido, a dinamização econômica do entorno, com novas possibilidades de diversificação de atividades econômicas que possam gerar emprego e renda é de extrema importância para a redução das desigualdades socioespaciais, amenizando, assim, os problemas gerados pelo crescimento periférico.

\section{NOTAS}

1. O conceito de "estrutura intra-urbana" tem por base as formulações de Bastide (1971) elaborada por Villaça, e parte da consideração de que o termo estrutura "corresponde a um todo cons- tituído de elementos que se relacionam entre si de tal forma que a alteração de um elemento ou de uma relação altera todos os demais elementos e todas as demais relações" (VILLAÇA, 2001, p. 12).

2. A análise do processo de ocupação do DF e entorno teve por base as conclusões da pesquisa "Gestão do Uso do Solo e Disfunções do Crescimento Urbano”, realizada em 1997 (IPEA, 2001).

3. A constituição de 1891 estabeleceu que as terras devolutas da União passariam a pertencer aos Estados, exceto as áreas incluídas no perímetro de $14.400 \mathrm{~km}^{2}$ destinado à implantação da capital no Planalto Central, a serem demarcadas futuramente. Um Decreto-Lei promulgado em 1967 determinou que fossem respeitados os direitos dos proprietários particulares, cujas posses constassem nos registros paroquiais, ou fossem baseadas em ações de usucapião até 1/1/1917, ou em documento de venda ou doação feitas pela União após a constituição de 1891. Assim, a implantação do DF não extinguiu a propriedade privada da terra. $\mathrm{O}$ resultado foi a existência de diferentes naturezas de propriedade: terras públicas, via desapropriação; terras particulares; e terras públicas e particulares em comum.

4. A estruturação intra-urbana da região tem como especificidade o aumento do uso residencial nas regiões periféricas sem o crescimento paralelo de atividades geradoras de empregos, fazendo com que o DF concentre cerca de $95 \%$ dos empregos formais da região, dos quais $76,4 \%$ estão na RA de Brasília, que abriga o centro principal (Dados Rais/MT 1999 - apud HOLANDA et al. 2000).

5. Algumas cidades-satélites chegam a distanciar-se mais de $30 \mathrm{~km}$ do Plano Piloto, como é o caso de Brazilândia (43 km), do Gama $(38 \mathrm{~km})$ e Ceilândia $(30 \mathrm{~km})$.

6. O município de Cabeceira Grande, desmembrado de Unaí em 1997, não integra a Ride oficialmente, apesar de ser limítrofe ao DF. No entanto, acreditando que este é um erro que deverá ser corrigido, ele foi incluído na área de análise.

7. Porcentual da população urbana em relação à população total. É calculado, geralmente, a partir de dados censitários, segundo a fórmula: Taxa de urbanização = população urbana / população total x 100 (população urbana dividida pela população total, multiplicado por 100).

8. A taxa média anual de crescimento demográfico do Brasil, entre 1991 e 2000, foi de 1,63\%. As Regiões Metropolitanas de São Paulo, Rio de Janeiro, Porto Alegre, Recife e Fortaleza tiveram taxas médias de $1,64 \% ; 0,73 \% ; 1,56 \% ; 1,50 \%$; e $2,44 \%$, respectivamente. A maior taxa média anual de crescimento dentre as grandes metrópoles foi a da Região Metropolitana de Curitiba, com 3,11\%. No Centro-Oeste, a Região Metropolitana de Goiânia teve taxa de $3,21 \%$ ao ano, no mesmo período.

9. No final da década de 70 e início dos anos 80 , a dificuldade de ocupação de terras pertencentes ao DF incentivou a intensificação de parcelamentos em municípios limítrofes, localizados principalmente na direção sudoeste a partir do DF, onde os lotes eram oferecidos a preços mais baixos e com maiores facilidades de pagamento, conforme mostra Paviani $(1987 ; 1989 ; 1991 ; 1996)$.

10. Essas taxas expressam, em termos porcentuais, o crescimento médio da população em um determinado período de tempo. Geralmente, considera-se que a população experimenta um crescimento exponencial também denominado geométrico.

11. Número de habitantes residentes de uma unidade geográfica em determinado momento, em relação à área dessa mesma unidade. A densidade demográfica é um índice utilizado para verificar a intensidade de ocupação de um território. Unidade: Habitante por metro quadrado (hab. $/ \mathrm{m}^{2}$ ).

12. Com o intuito de expressar a divisão funcional estabelecida no processo de estruturação interna da região, serão utilizados neste artigo três diferentes recortes espaciais, abrangendo os municípios que compõem a Ride. Será denominado Entorno Imediato o con- 
junto de municípios goianos vizinhos ao DF que tiveram seus processos de ocupação e crescimento demográfico diretamente relacionados à expansão urbana do DF - Águas Lindas de Goiás, Santo Antônio do Descoberto, Planaltina, Valparaíso de Goiás, Luziânia, Novo Gama e Cidade Ocidental. Os demais municípios que compõem a Ride, e que não sofreram impacto direto do processo de expansão urbana periférica do DF, serão denominados Entorno Distante.

13. Na análise sobre a migração foi necessária uma opção metodológica diferenciada para os dados dos Censos Demográficos realizados pelo Instituto Brasileiro de Geografia e Estatística - IBGE em 1980 e 1991, e o Censo de 2000. Nos casos em que não foi possível identificar a residência anterior (origem por municípios), foi feita a opção pela adoção da informação referente à data fixa. Para efeito de comparabilidade, nesses casos foi utilizada para os Censos de 1980 e 1991, a informação referente à residência anterior, para os migrantes com menos de cinco anos de residência; e, para o Censo de 2000, a informação referente ao município de residência em 31/7/1995. Apesar de reconhecer que as informações não são comparáveis em termos de volumes - principalmente nos casos de múltiplos movimentos no período intercensitário - a opção foi feita em função de ser essa a única possibilidade de identificar o município de origem dos fluxos migratórios para o Censo de 2000. A informação referente à data fixa tem como vantagem formal, nos dados demográficos, a determinação clara do período referente à migração. No entanto, no caso da migração intrametropolitana, movimento em que são mais freqüentes as reimigrações de curto prazo, a informação de data fixa tem como desvantagem a perda dos movimentos ocorridos no primeiro qüinqüênio, além do fato de essa informação considerar apenas as pessoas maiores de cinco anos. Para maiores detalhes sobre as diferenças entre esses dois tipos de informação, ver Carvalho e Rigotti (1998).

14. O Índice de Eficácia Migratória é calculado a partir do quociente entre migração líquida e migração bruta, sendo que os valores positivos próximos a um (1) indicam áreas de atração de população, e os valores negativos próximos a (-1) indicam áreas de evasão de população. Valores próximos a zero indicam área de grande circulação de população (imigração próxima à emigração). Na análise desse índice foi utilizada a tipologia estabelecida por Baeninger (1999), sendo os diferentes espaços regionais classificados, segundo os IEM, em: área de forte evasão migratória (-1,00 a -0,51); área de média evasão migratória (-0,50 a -0,30); área de baixa evasão migratória $(-0,29$ a $-0,01)$; área de rotatividade migratória $(0,00$ a 0,09$)$; área de baixa absorção migratória $(0,10$ a 0,29); área de média absorção migratória $(0,30$ a 0,50) e área de forte absorção migratória $(0,51$ a 1,00$)$.

15. Na verdade, mesmo os fluxos intra-regionais mais significativos - emigração do DF para os municípios da região - são interestaduais, uma vez que a região é constituída por três UFs (DF, Goiás e Minas Gerais). No entanto, para melhor compreensão da migração intra-regional, esses fluxos serão denominados intra-regionais, ou intrametropolitanos, ainda que envolvam diferentes UFs.

16. Antes mesmo da inauguração da capital, durante o processo de sua construção, o recrutamento de trabalhadores que iriam tornar realidade o projeto do Governo Federal deu origem a um intenso fluxo migratório, baseado em expectativas supervalorizadas de empregos e melhores condições de vida. As condições especiais de mercado de trabalho e salários eram o principal atrativo para a população que não encontrava condições satisfatórias de vida em seus Estados de origem. As expectativas de melhoria das condições de vida fundamentavam-se na grande oferta de empregos, em salários mais elevados que nos locais de origem, na não-limitação de trabalho em horas extras e no fato de o treinamento ser realizado no próprio local de trabalho - o que dispensava experiência anterior e possibilitava rápida ascensão profissional, em função das habilidades recém-adquiridas (HOLSTON, 1993).
17. Goiás havia recebido grande fluxo de imigrantes na década anterior, pela expansão da fronteira agrícola - o que certamente favoreceu nova etapa migratória em direção a Brasília.

18. A taxa de migração estabelece uma relação entre o volume do fluxo migratório e a população média da região.

19. Infelizmente, os dados censitários não nos permitem medir os fluxos pendulares entre as Regiões Administrativas de localização periférica e o Plano Piloto, o que certamente elevaria os volumes verificados.

20. Termos utilizados como títulos de textos escritos por Campos e Gouvêa (apud PAVIANI, 1989).

21. Segundo os dados da PED para julho de 2003, a taxa de desemprego era de $23 \%$ da PEA, sendo o volume de desempregados estimado em 263,1 mil pessoas.

\section{REFERÊNCIAS BIBLIOGRÁFICAS}

BAENINGER, R. Interiorização da migração em São Paulo: novas territorialidades e novos desafios teóricos. In: ENCONTRO NACIONAL DE ESTUDOS POPULACIONAIS, 14., Anais... Caxambu, 2004.

. Novos espaços da migração no Brasil: anos 80 e 90. In: ENCONTRO NACIONAL DE ESTUDOS POPUlACIONAIS, 12., Anais... Caxambu, 2000.

Região, metrópole e interior: espaços ganhadores e espaços perdedores nas migrações recentes - Brasil, 1980-1996. Campinas: IFCH/Unicamp, 1999.

BASTIDE, R. Usos e sentidos do termo “estrutura”. São Paulo: Edusp/Ed. Herder, 1971.

BRITO, F. Minas e o Nordeste: perspectivas migratórias dos dois grandes reservatórios de força de trabalho. In: ENCONTRO NACIONAL DE MIGRAÇÃO, 2., Anais... Ouro Preto: Abep/GT de Migração, 1999.

CAIADO, M.C. Estruturação intra-urbana e contrapartidas sociodemográficas: a diferenciação socioespacial da população na Região do Distrito Federal e Entorno. Tese (Doutorado) Instituto de Filosofia e Ciências Humanas da Unicamp, Campinas, 2004.

CARVALHO, J.A.M.; RIGOTTI, J.I.R. Análise das metodologias de mensuração das migrações. In: ENCONTRO NACIONAL SOBRE MIGRAÇÃO, Anais... Curitiba: Ipardes/Funuap, 1998.

CUNHA, J.M.P. Mobilidade populacional e expansão urbana: o caso da Região Metropolitana de São Paulo. 1994. Tese (Doutorado) - Instituto de Filosofia e Ciências Humanas, Universidade Estadual de Campinas, Campinas, 1994.

HOLANDA, F.; MOTA, A.N.P.; SOARES, L.; GARCIA, P.M. Brasília já nasceu excêntrica? Brasília: Departamento de arquitetura e urbanismo/UBN, 2000.

HOLSTON, J. A cidade modernista: uma crítica de Brasília e sua utopia. São Paulo: Companhia das Letras, 1993.

IBGE. Censos Demográficos 1980, 1991 e 2000. Rio de Janeiro.

IPEA, Gestão do uso do solo e disfunções do crescimento urbano. Brasília, 2001. (Relatório de pesquisa, n. 2). 
PAVIANI, A. (Org.) Brasília: moradia e exclusão. Brasília: Ed.UnB, 1996. (Coleção Brasília).

(Org.). Movimentos populares em Brasília. Brasília: Ed. UNB, 1991. (Coleção Brasília).

Brasília, a metrópole em crise. Ensaio sobre urbanização. Brasília: Ed.UnB, 1989.

(Org.). Urbanização e metropolização. A gestão dos conflitos em Brasília. Brasília: Ed. UnB, 1987.

PACHECO, C.A.; PATARRA, N.L. Movimentos migratórios nos anos 80: novos padrões? Migração, condição de vida e dinâmica urbana: São Paulo 1980-1993. Campinas: Unicamp, 1997.

SASSEN, S. The global city: New York, London, Tokyo. 2. ed. New Jersey: Princeton University Press, 2001.
VILLAÇA, F. Espaço intra-urbano no Brasil. São Paulo: Studio Nobel, Fapesp, Lincoln Institute, 2001.

Maria Célia Silva Caiado: Arquiteta, Doutora em Demografia Pesquisadora do Núcleo de Economia Social Urbana e Regional do Instituto de Economia da Unicamp e pós-doutoranda pelo $C N P Q$ no Núcleo de Estudos da População da Unicamp (mccaiado@uol.com.br)

Artigo recebido em 16 de setembro de 2005 .

Aprovado em 17 de novembro de 2005. 